\title{
A Study for Challenges in Service Delivery within the Procurement Function of the Tourism Industry in Hainan
}

\author{
Hongjun Fan ${ }^{1, a,}$, Dan Cai ${ }^{2, b}$ and Fang Chen ${ }^{1, c}$ \\ ${ }^{1}$ Tourism Management School of Hainan College of Economics and Business, Haikou571127, China \\ ${ }^{2}$ Tourism College of Hainan University, Haikou570208, China \\ ahkfhj2006@163.com, b33259000@qq.com, 'Juliachen6467@126.com \\ *corresponding author
}

Keywords: challenges, service delivery, procurement function, tourism industry, Hainan.

\begin{abstract}
The study aimed at analyzing the challenges of procurement function on service delivery of the tourism industry in Hainan. The study was guided by three specific objectives including; evaluating the influence of political patronage on service delivery, to determine the effect of community participation on service delivery and to find out the relationship between composition of procurement committees and service delivery. To achieve the study objectives accordingly, the research used descriptive survey design and targeted the procurement staff of the tourism industry companies in Hainan. A census study was therefore conducted among all the procurement staff where questionnaire was used to obtain information from the respondents. Data analysis was conducted using Statistical Package for Social Sciences version 21. The finding indicated that political patronage, lack of community involvement and inadequate composition of procurement committees were major challenges facing procurement processes of tourism industry in Hainan Province. The findings led to recommendations that laws should be enacted to provide amicable remedies for misuse of political positions to influence provincial procurement processes. Further, there should be community involvement in the procurement of major projects within the province. Additionally, there is need for adequate representation to the procurement committees which should be based on academic qualifications and experience to enhance service delivery.
\end{abstract}

\section{Introduction}

Emergence of global economy, increased decentralization of government function, greater discretions power officials and weakness of the current procurement system have led to need of regulating procurement in new ways, hence need for reforms to solve these emerging challenges in the public procurement of the tourism industry. Success of public procurement system of the tourism industry reforms depends on a clear articulation and understanding of what the legal and regulatory framework seeks to achieve. Services whose delivery and financing is often decentralized include but are not limited to education, health, water, sanitation, public transport and infrastructure, roads maintenance, fire, housing and social welfare. These are services which should have 'little inter-jurisdictional spillover effect. The term is used to refer to anything from the de-concentration of administrative responsibilities within a single government agency to the devolution of power over all basic local services to semi-autonomous local authorities. It is also used to describe the transfer of power to a wide range of geographical levels, from the regional or state level to that of local governments or communities'.

Public procurement of the tourism industry is an important function of government for several reasons. First, the sheer magnitude of procurement outlays has a great impact on the economy and needs to be well managed in the tourism industry. Indeed, in all countries in the world, estimates of the financial activities of government procurement managers are believed to be in the order of 10\%-30 \% of GNP (Callender \& Mathews, 2012). Efficiently handling this size of procurement 
outlays has been a policy and management concern as well as a challenge for public procurement practitioners. Their ability to accomplish procurement objectives and policies is influenced very much by internal forces including Interactions between various elements of the public procurement systems, various officials and organizations in the three branches of government, and various actors and sub-agencies within a department or executive agency and actors and organizations external to sub-agencies (Elliott, 2014).

Devolved government clearly represents a major component of Australian public sector administration. A trend to increased delivery of government services through the non-government sector has also been evident in other countries. In the UK it has increased significantly, with the greater participation of various community and not-for-profit bodies in service provision. The function of procurement has grown tremendously in China over the last ten years. The increased interest in procurement has however led to questions whether procurement function is achieving service delivery to the tourism industry in Hainan public while ensuring value for money. Consumers of procurement services look for assurances that procurement activities are indeed being handled professionally (Wamae, 2014).

The law should therefore address on how to deal with these seniors and powerful politicians in order to tame their negative influence in this sector. And the corruption in public procurement is also facilitated by lack of transparency and elitist process of public procurement whose demands are invariably beyond the accessibility of ordinary tenders. The devolved government, proposed during the making of the new constitution, is primarily geared towards achieving two main objectives. It Involve the people in governance, Allow better supervision and implementation of policies at the grass root level. The responsibilities of the provincial government assembly include: Exercising the powers of enacting laws at the provincial level, acting as an oversight instrument on the provincial executive Approval of plans and policies for smooth operation and management of resources and province institutions. When public institutions fail to meet the expectations of consumers in service delivery, the ripple effects result in grave consequences on political, social and economic growth of a state. The quality of utility service delivered to the private sector is generally poor and this results increasingly in businesses incurring huge unplanned costs. Public services are water, electricity, waste management, health, housing, business registration and road networks. Further to this, making sure they reach the people and places they are intended to for social and economic growth. However, issues that resurrect public displeasure are the manner in which these services are delivered by public institutions concerned. Complaints from clients/consumers are that public officials are not responsive and mishandle businesses and people who approach them for services. It is against this background that this study that the study sought to analyze the challenges of procurement function on service delivery of the tourism industry in Hainan.

The devolution of power, authority and resources to sub-national entities is intended to make governance more responsive to the needs of the people. It is also intended to make governments more accountable to the local people. It has been proven that indirect procurement of goods not directly involved in the core business be it product or service delivery usually constitute 30-60 percent of a firm's total expenditure. Non-value adding activities such as data entry, correcting of errors in paperwork, expediting or solving quality problems and suppliers chasing the procurement function for payment were also seen to be core contributor to procurement being a bottleneck in an organization. These loopholes allowed for unethical procurement activity such as bribery and corruption similarly contractors who have no capacity and expertise end up getting contracts which they will not perform leading to loss of public funds. There is need for this department to perform and this can only be seen when the individual performance are raise, this will translate to better service delivery in public sector and profitability in the private sector. However, issues that resurrect public displeasure are the manner in which these services are delivered by public institutions concerned. Further, the function of procurement has grown tremendously in Hainan over the last ten years. The increased interest in procurement has however led to questions whether procurement function is achieving service delivery to the Hainan public while ensuring value for money. Consumers of procurement services look for assurances that procurement activities are indeed being handled 
professionally. Therefore, this study focused on areas such as political patronage, community participation, composition of procurement committees and bureaucracy in public procurement at the Provincial level of government.

\section{The challenges of procurement function on service delivery in Hainan}

\subsection{Influence of Political Patronage on Service Delivery}

The political patronage manifests itself in public appointments; judicial, legal and policy frameworks; politics of ethnicity and tribal balancing; corruption and impunity in public service; and economic influences of corruption. The dependent variable in the current study is operationalization of Public Procurement Law in Hainan. This study opines that the operations of Public Procurement and Disposal Act and the backup laws meant to streamline the management of public procurement in the province have been undermined by the political culture in the province rendering them largely ineffective. The public procurement sector reform in developing countries has historically gone through three main phases: increased emphasis on the importance of capacity building, fiscal stability, and focus on the actual quality of public services delivered. However, this in effect alienates the more complex and usually undercover influence of politics on the key sectors of public service such as public procurement of the tourism industry, and hence the need to unravel the influence of political patronage on the operationalization of Public Procurement Law in Hainan. Political patronage works in governments which tend to be unpopular with the citizenry to ensure that only their narrowly-drawn and often ethnic constituencies have access to public resources, such as lucrative public procurement contracts. And public resources are therefore a means through which such governments "purchase" legitimacy to remain in power. Common corrupt practices in public procurement involve public officers, often under the influence of powerful politicians and businessmen, only inviting preferred firms, favoring certain firms at the short-listing stage, designing tender documents to favor particular firms and releasing confidential information. The procurement system is manned by junior officers, who are powerless to correct any anomalies and may easily be manipulated by their seniors and powerful politicians.

\subsection{The Effect of Community Participation on Service Delivery}

Community participation implies consultation and working with and not for people. People will participate and contribute meaningfully to something they feel part of, identify with, and associate with their efforts. Community participation to be meaningful the final decision must be made by people. However, our communities sometimes do not utilize this opportunity efficiently at all points. The planned social change can only be realized through the participation of the community in all the stages of the development process. Citizen participation in governance and public service delivery is increasingly pursued in a bid to improve the performance of governments. Indeed, improving delivery of public services continues to be a key objective that has occupied the agenda of public administrators and researchers. Faced with constraints and failures of centralized service delivery especially at the local level, governments have turned to decentralized mechanisms of service delivery (Robinson, 2017). Decentralization has involved 'the transfer of administrative, fiscal and political powers and functions of the central government to lower-level governments. The number of countries adopting it, and the magnitude of implementation has made decentralization a key global trend in public administration and management in the last three decades (Steiner, 2015). In a World Bank policy research paper on decentralization and service delivery, in the period 1990-2015 'over 75 countries had attempted to transfer responsibilities of the state to lower tiers of government'. This has been in the context of increasing focus on democratic governance, whose core principles include participation, transparency, accountability, subsidiarity and separation of powers. In this context, decentralization is seen as a conducive means of achieving the principles, providing an institutional framework at the sub-national level through which groups and citizens can organize themselves and participate in political and economic decisions affecting them'. Such an arrangement is based on the 
assumption that the local government units will 'be more responsive to the needs of the citizens and take their preferences into account in determining the type of services to be provided, the level of resources required, and the optimal means of ensuring effective delivery'. This requires local government units that have the political space and capacity to make and effect decisions. It is for this reason that decentralization has been favored and promoted internationally. The first and most obvious issue is that community participation includes the involvement of a substantial number of people into community activities. The direct involvement of ordinary people in design, implementation and evaluation of planning, governance and overall development programmes at grassroots level, has become an integral part of democratic practice. Democratic policies state that activities of the community are not considered to be the special vicinity of a knowledgeable few, perhaps the same elite leadership who have always run community affairs, but are the business of everyone in the community.

\subsection{The Relationship between Composition of Procurement Committees and Service Delivery}

A company's board of directors should determine whether or not a person qualifies as an audit committee financial expert. The board should consider all of the facts and circumstances surrounding the person's qualifications, including the person's personal and professional integrity and the breadth and level of the person's education, service in relevant positions and duties in such positions, experience and familiarity with financial statements, past experience on audit committees and other relevant experiences. The proposed rules contained a list of qualitative factors (that are not included in the final rules) to be considered in evaluating whether or not a person qualifies as a committee financial expert. Although such factors were not intended as an exhaustive list of factors and are not included in the final rules, they provide good guidance for the types of factors that should be taken into account in determining whether or not a person qualifies as an audit committee financial expert. A Finance Committee may be especially valuable and necessary on a board where a majority of members are uncomfortable with fiscal matters and/or numbers. This is often the case on the boards of human service and community-based organizations, where many members may be either recipients of services or people who are heavily focused on the interpersonal and emotional, rather than the more mathematical and logical aspects of their intelligence; To act as an advisory panel to the financial operation. Especially if it's made up of people with expertise, the committee can provide advice on fiscal issues in general, correcting inefficiencies and misguided accounting practices, dealing with anticipated shortfalls or surpluses, investing; To evaluate both the financial operation and the people in charge of it from a position of knowledge. A committee that works closely with the financial operation is in a much better position to monitor and evaluate performance than is a board that doesn't have that connection. It makes the financial operation accountable, and can - and should let the board know when someone's doing a particularly good job, as well as when someone isn't working up to standard; To help in the hiring of fiscal staff or a new director. Having intimate knowledge of the financial operation gives committee members a much better perspective on the skills and temperament needed to do the jobs well; To make the audit easier, both by assisting the fiscal operation in gathering material and cleaning up records, and by working with the auditors beforehand to make sure that they have everything they need to complete the audit efficiently and effectively; To interpret the audit for the rest of the board.

\section{Research Findings and Analysis}

From the findings, majority were between ages 31-40 years as indicated by $53 \%$. In addition, the employees majorly comprised of male at $66 \%$ while their female counterparts totaled to $34 \%$. Majority of the employees were holders of a Bachelors' degree as their count stood at $56 \%$. A section of the respondents at $25 \%$ had master's degree while another $13 \%$ were tertiary college certificate holders. These results showed that Hainan provincial government has set the bachelor's degree as the basic qualification required to serve within the supply chain department of the tourism industry. Further, in line with the new constitution, there is a considerable number of women employed. 
Further, the age bracket indicated that most employees within the province were comprised of the youth.

\subsection{Influence of Political Patronage on Service Delivery}

According to table 1, it was established that political patronage is founded on ethnicity, corruption and impunity in public service. This result was evidenced by majority of the respondents who agreed (mean=3.84) on the matter. Further, the opinion of the respondents seemed to be more convergent on the matter as indicated by $(\delta=.987)$ as compared to other variables under political patronage. The findings also revealed as agreed by majority of the respondents (mean=3.69) that public procurement focuses on the actual quality of public services delivered. Further, respondents were not sure (mean=3.59) whether political patronage works in governments which tend to be unfamiliar with the citizens. The table also showed that political patronage encourages use of resources to purchase legitimacy to remain in power instead of service delivery as evidenced by a mean of3.75. With a mean of3.84, it was agreed upon by the respondents that common corrupt practices in public procurement involve officers under the influence of powerful politicians. The research also reported that the presence of junior officers manning procurement system in public sector is powerless to correct anomalies by their senior and powerful politicians. This was evidenced by a mean of 3.78 and a standard deviation of 1.289 which showed how respondents' opinions were largely varied than any other variable in the table.

Table 1 Political Patronage and Service Delivery

\begin{tabular}{|l|c|c|c|c|c|}
\hline Content & Non & Min & Max & Mean & Std.Dev. \\
\hline Political patronage is founded on ethnicity, corruption and impunity & 32 & 1 & 5 & 3.84 & .987 \\
\hline Public procurement focuses on quality ofservices delivered & 32 & 1 & 5 & 3.69 & 1.148 \\
\hline Political patronage works in unfamiliar governments & 32 & 1 & 5 & 3.59 & 1.241 \\
\hline Political patronage encourages misuse of resources & 32 & 1 & 5 & 3.75 & 1.218 \\
\hline $\begin{array}{l}\text { Corrupt practices in public procurement involves powerful } \\
\text { politicians }\end{array}$ & 32 & 1 & 5 & 3.84 & 1.194 \\
\hline $\begin{array}{l}\text { Junior officers in procurement system cannot correct anomalies } \\
\text { bytheir senior politicians }\end{array}$ & 32 & 1 & 5 & 3.78 & 1.289 \\
\hline
\end{tabular}

\subsection{The Effect of Community Participation on Service Delivery of the tourism industry}

Table 2 ascertained that respondents agreed (mean=4.25) that community participation implies working with people and not for people. It was also revealed that community participation promotes meaningful contribution by community members as shown by a mean of 4.25 . In addition, it was agreed upon that participation promotes realization of planned social change in all stages of the development process as evidenced by a mean of 4.06. Consequently, It was agreed (mean=4.38) upon by majority of the respondents that citizen participation in public procurement is aimed at improving performance. When respondents were asked whether decentralized procurement activities enhances participation, majority agreed (mean $=4.25$ ) and that this would improve service delivery. The table also showed that participation in public procurement activities ensures the government is responsive to the needs of the citizens in terms of service delivery as it was agreed (mean=4.25) by majority of the respondents. Further, the standard deviation of 0.672 showed that respondents seemed to agree more that public participation in procurement activities enhances the responsiveness of the government towards citizens' needs. However, respondents the opinions of the respondents were greatly varied on whether decentralized procurement enhances public participation as indicated by a standard deviation of 1.047 which was higher than any value in the table. 
Table 2 Community Participation and Service Delivery

\begin{tabular}{|l|c|c|c|c|c|}
\hline \multicolumn{1}{|c|}{ Content } & Non & Min & Max & Mean & Std.Dev. \\
\hline Community participation entails working with the people & 32 & 2 & 5 & 4.25 & .916 \\
\hline Community participation promotes contribution by the community & 32 & 1 & 5 & 4.25 & .803 \\
\hline Participation promotes realization of planned social change & 32 & 2 & 5 & 4.06 & .759 \\
\hline Community participation promotes performance & 32 & 1 & 5 & 4.38 & .833 \\
\hline Decentralized procurement enhances participation & 32 & 1 & 5 & 4.25 & 1.047 \\
\hline Participation ensures the government is responsive to citizen needs & 32 & 2 & 5 & 4.25 & .672 \\
\hline
\end{tabular}

\subsection{Composition of Procurement Committees and Service Delivery}

According to Table 3, it was agreed (mean=3.81) that establishment of procurement committees is envisaged in the constitution. However, respondents were not sure (mean=3.19) whether composition of procurement committees is based on academic or professional qualification as far as their opinions were greatly dispersed ( $\delta=1.491$ ). The findings showed that respondents agreed (mean=4.38) that political affiliation affected the nominees to the procurement committees. Further, respondents could not tell whether committee members were selected based on experience on past position held as indicated by a mean of 3.28. It was overwhelmingly disagreed upon by majority of the respondents that members of the procurement committees adhere to public procurement and disposal Act. It was disagreed upon that public procurement committees are independently constituted and function independently. In addition, respondents had converging opinions that public procurement Act was adhered to as indicated ( $\delta=.692$ ).

Table 3 Composition of Procurement Committees and Service Delivery

\begin{tabular}{|l|c|c|c|c|c|}
\hline \multicolumn{1}{|c|}{ Content } & Non & Min & Max & Mean & Std.Dev. \\
\hline Establishment of procurement committees is guided by constitution & 32 & 1 & 5 & 3.81 & 1.148 \\
\hline Procurement committees are composed based on education & 32 & 1 & 5 & 3.19 & 1.491 \\
\hline Political affiliation affects procurement committee nomination & 32 & 1 & 5 & 4.38 & .912 \\
\hline Selection of committee members is based on experience & 32 & 2 & 5 & 3.28 & 1.114 \\
\hline Public procurement and disposal Act is adhered to & 32 & 1 & 5 & 2.41 & .692 \\
\hline Public procurement committees function independently & 32 & 1 & 5 & 2.38 & .762 \\
\hline
\end{tabular}

\section{Inferential Analysis}

From subsequent correlation analysis, there was a significant positive relationship $(r=0.376)$ between political patronage and service delivery at 95\% level of significance in Hainan provincial Government. The common corrupt practices in public procurement involve public officers, often under the influence of powerful politicians and businessmen, only inviting preferred firms, favoring certain firms at the short-listing stage, designing tender documents to favor particular firms and releasing confidential information thereby undermine service delivery. Further, there was a positive moderate relationship $(r=0.231)$ at $95 \%$ level of significance between community participation and service delivery in Hainan provincial Government. The public and citizen participation in political and economic decisions makes the government to be more responsive to the needs of the people and take their preferences into account in determining the type of services to be provided.

Committee members who are uncomfortable with fiscal or procurement procedures may negatively influence service delivery. The study further carried out a multivariate regression analysis was used to determine the significance of the relationship between the challenges of procurement function and service delivery pooled together. Table 4 gives the model summary of the regression. 
Table 4 Multiple Linear Regression Analysis Model Summaries

\begin{tabular}{|l|c|c|c|c|}
\hline Model & R & R Square & Adjusted R Square & Std. Error of Estimate \\
\hline 1 & $.693 a$ & .551 & .4802 & .95742 \\
\hline
\end{tabular}

a. Dependent Variable: Service delivery

The results in Table 4 showed that the value obtained for $\mathrm{R}$, which is the model correlation coefficient was $\mathrm{R}=0.693$ which was higher than any zero order value in the table. This indicated that the model improved when more variables were incorporated when trying to analyze the challenges of procurement function on service delivery in the Provincial government of Hainan. The adjusted $r$-square value of, $r=0.4802$, also indicated that the multiple linear regression model could explain for approximately $48 \%$ of the variations in the challenges of procurement function on service Delivery.

Table 5 Regression Model

\begin{tabular}{|l|c|c|c|c|c|}
\hline (Constant) & 7.185 & 2.263 & & 2.408 & 016 \\
\hline Political Patronage & 489 & 262 & 345 & 1.863 & 072 \\
\hline Community Participation & 095 & 160 & 125 & 595 & 556 \\
\hline $\begin{array}{l}\text { Composition of procurement } \\
\text { Committees }\end{array}$ & 057 & 144 & 065 & 395 & 695 \\
\hline
\end{tabular}

From the full regression model in Table 5, the regression equation was obtained. Using the unstandardized beta coefficients, the following regression equation was developed.

$$
\mathrm{Y}=7.185+0.489 \mathrm{X} 1+0.095 \mathrm{X} 2+0.057 \mathrm{X} 3
$$

From the full regression model, the beta values were obtained which explained the regression equation. The standardized beta coefficients give a measure of the influence of each variable to the model. Regarding the inference of challenges of procurement function of the tourism industry on service delivery, the study revealed that political patronage posed the greatest challenge to service delivery (Beta $=0.489$ ), followed by inadequate community participation (Beta $=00.95$ ) and finally management the composition of procurement committees which had (Beta $=0.057)$

\section{Conclusions}

It was concluded that political patronage is founded on ethnicity, corruption and impunity in public service while public procurement focused on the actual quality of public services delivered. Further, it was concluded that political patronage encourages use of resources to purchase legitimacy to remain in power instead of service delivery. It was also concluded that community participation promotes meaningful contribution by community members in undertaking procurement practices. Service delivery would greatly improve if procurement activities are decentralized as a result of enhanced participation. Public participation in public procurement activities also ensures that the government is responsive to the needs of the citizens in terms of service delivery. The findings led to the conclusion that there was significant awareness on the fact that establishment of procurement committees is envisaged in the constitution. The researcher otherwise concluded that the composition of procurement committees were never based on professional qualification and relevant to procurement for this matter. Further, it was concluded that members of the procurement committees did not adhere to public procurement and disposal Act and that public procurement committees are not independently constituted besides not functioning independently. The findings led to the conclusion that service delivery in the context of public procurement of which corruption has been a major impediment with respect to procurement function. 


\section{Acknowledgments}

This work was financially supported by the 2017 Planning Research Project of the National Tourism Administration of the P.R.C., "The practice and exploration of the Modern Apprenticeship of Tourism Management Major in Higher Vocational Colleges ” (NO:WMYC201730078).

\section{References}

[1] Callender, G., \& Matthews, D. (2012). Government purchasing: An evolving profession?. Journal of Public Budgeting Accounting and Financial Management, (12), 272-290.

[2] Elliot, M. (2014). How procurement managers view low cost countries and geographies: a perceptual mapping approach. International Journal of Physical Distribution \& Logistics Management, 38(3), 224-243.

[3] Wamae, W. (2014). Role of procurement function in enhancing performance in devolved government: A case of Machakos County. International Journal of Social Sciences and Entrepreneurship, 1(11), 168- 190 .

[4] RoK. (2013). Report on county governments finance performance for March to June. Nairobi: Office of Controller of Budget.

[5] RoK. (2013). The public procurement and disposal regulations. Nairobi: Government Printer.

[6] Steiner, S. (2015). Decentralization and Poverty Reduction: A Conceptual Framework for the Economic Impact.”(June). 